\title{
Hypoxanthine Uptake in Isolated Rat Renal Cortical Tubule Fragments
}

\author{
John W. Foreman and Stanton Segal, Division of Biochemical Development and \\ Molecular Diseases, Children's Hospital of Philadelphia, and the Departments of \\ Pediatrics and Medicine, University of Pennsylvania School of Medicine, \\ Philadelphia, Pennsylvania 19104
}

\begin{abstract}
A B S T R A C T Isolated renal tubule fragments prepared from adult Sprague-Dawley rats were used to study the cellular uptake of hypoxanthine. This uptake was rapid, reaching a steady state after $30 \mathrm{~min}$ of incubation. Analysis of the intracellular pool during the initial uptake and at the steady state revealed a concentration gradient of hypoxanthine consistent with active transport, although only one-third of the transported hypoxanthine remained unmetabolized. The remainder of the transported hypoxanthine was converted to inosine and inosinic acid, but detectable conversion to uric acid was not noted. A kinetic analysis of uptake revealed that two systems for cellular entry of hypoxanthine existed with $K_{\mathrm{m} 1}=0.005$ and $K_{\mathrm{m} 2}$ $=0.80 \mathrm{mM}$. Hypoxanthine uptake at physiologic concentrations was oxygen, sodium, and temperature dependent, but the addition of metabolic fuels and alteration of the medium $\mathrm{pH}$ over the range of from 6.1 to 7.4 had no effect. Adenine, guanine, and inosine inhibited the uptake of hypoxanthine via the low- $K_{m}$ system which mediates the majority of uptake at physiologic levels. Xanthine, uric acid, and probenecid inhibited uptake via the high- $K_{\mathrm{m}}$ system, but did not affect uptake via the low- $K_{\mathrm{m}}$ system. The data indicate that hypoxanthine at physiologic levels is transported into the renal tubule cell via a system different from that for other oxypurines.
\end{abstract}

\section{INTRODUCTION}

The elucidation of the nature of the renal excretion of oxypurine (considered here to be xanthine and hypoxanthine although uric acid is also an oxypurine) is

This work was presented in part at the VIIth International Congress of Nephrology, Montreal, Canada, June 1978.

Received for publication 9 November 1978 and in revised form 18 December 1978. important in several areas of medicine. The use of the xanthine oxidase inhibitor allopurinol (4-hydroxypyrazolo[3,4- $d$ ]pyrimidine) as an adjunct to cancer chemotherapy (1) and in the treatment of gout $(2,3)$ leads to an increased renal excretion of oxypurines. The LeschNyhan syndrome, which is characterized by a defective reuse of purine bases leading to a marked increase in de novo purine biosynthesis, is also associated with an increased renal excretion of oxypurines, which is augmented upon the administration of allopurinol (4). Xanthinuria is another disease in which an understanding of the renal handling of oxypurines is necessary for defining the pathogenesis and planning therapy. The precise nature of oxypurine handling by the kidney is unknown. Clearance studies with normal plasma oxypurine concentrations have demonstrated net tubular reabsorption (5), but net tubular secretion is observed with raised plasma concentrations (5-8). Recent data suggest that hypoxanthine and xanthine are handled differently by the kidney (8).

Information concerning the handling of oxypurines by renal cortical cells derived from in vitro experiments is limited. In the studies of Berndt (9), the uptake of hypoxanthine by rabbit renal cortical slices was slow, requiring $4 \mathrm{~h}$ to reach a steady state. Under these conditions a kinetic analysis of the oxypurine transport process was difficult to perform. On the basis of inhibition studies, however, there was evidence for separate transport properties of hypoxanthine and xanthine into renal tubule cells. The present work examines the kinetic parameters of hypoxanthine uptake in isolated rat renal cortical tubule fragments. Isolated tubules offer advantages over cortical slices of better oxygenation and substrate availability to the tubule cells. The more rapid substrate uptake by isolated tubules has made possible a kinetic analysis of transport parameters and enabled us to delineate the characteristics of two saturable transport systems that mediate hypoxanthine uptake. 


\section{METHODS}

The preparation of isolated tubule fragments was performed by a modification of the procedure by Burg and Orloff $(10,11)$. Adult, male Sprague-Dawley rats (Charles River Breeding Laboratories, Wilmington, Mass.), weighing 150-200 g, were fed ad libitum on Purina rat chow until they were killed by decapitation. The kidneys were quickly removed, stripped of the capsule, and placed in iced Krebs-Ringer bicarbonate buffer (KRB) ${ }^{1}$ at $\mathrm{pH} 7.4$ (12). With a Stadie-Riggs microtome, two slices of cortex were taken from each slide, and the remainder of the cortex was dissected by hand. The cortex was finely minced and placed in $0.375 \% \mathrm{wt} / \mathrm{vol}$ collagenase solution in $\mathrm{KRB}, 0.5 \mathrm{ml}$ for each kidney stripped of cortex. After a 45-min digestion at room temperature, KRB was added to the flask in an amount equal to twice the original incubation volume. This was then spun in a model UV International centrifuge (Damon/ IEC Div., Damon Corp., Needham Heights, Mass.) at $40 \mathrm{~g}$ for $1.5 \mathrm{~min}$ at room temperature. The pellet was resuspended in the same volume of KRB and the procedure repeated three times, the last suspension being filtered through three layers of surgical gauze. Bicarbonate buffer and fetal calf serum were added to the filtrate so that there was $5-15 \mathrm{mg}$ of tubules $/ \mathrm{ml}$ of buffer that contained $5 \%$ calf serum.

Uptake studies were performed as previously described with continuous gassing in $95 \% \mathrm{O}_{2} 5 \% \mathrm{CO}_{2}$ at $37^{\circ} \mathrm{C}$ unless otherwise stated (11). The tissue pool of radioactivity was extracted in $1 \mathrm{ml}$ of water by boiling for $3 \mathrm{~min}, 0.2 \mathrm{ml}$ of the media and the aqueous tissue extract were assayed for radioactivity in $10 \mathrm{ml}$ of Econofluor:ethanol (35:14) (New England Nuclear, Boston, Mass.) by liquid scintillation techniques. Distribution ratios of radioactivity (the ratio of counts per minute per milliliter of intracellular fluid to counts per minute per milliliter of medium were calculated as described previously (13). The intracellular fluid volume was calculated as the difference between the total tissue fluid (wet weight - dry weight) and the volume of "trapped fluid". These volumes have been determined previously in isolated cortical tubule fragments from adult Sprague-Dawley male rats and the total tissue fluid is $80 \%$ of the wet weight and the "trapped fluid" is $26 \%$ of the wet weight (11).

In concentration dependence studies, tubules were incubated for $3 \mathrm{~min}$ with $0.05 \mu \mathrm{Ci} / \mathrm{ml}\left[{ }^{14} \mathrm{C}\right]$ hypoxanthine and unlabeled substrate to give the desired final concentration over the range of from 0.0066 to $0.2873 \mathrm{mM}$. The observed transport kinetic parameters were determined from a Lineweaver-Burk plot with a Monroe model 1775 (Monroe, The Calculator Co., Litton Industries, Morristown, N. J.) programmable calculator to obtain the best fit by the least squares method. For assessment of their inhibitory capacity, various compounds were added to the incubation medium simultaneously with the hypoxanthine and incubated $3 \mathrm{~min}$. To analyze the nature of the purine base inhibition, adenine was added to the incubation medium to give a final concentration of $0.83 \mathrm{mM}$, whereas the concentration of hypoxanthine was varied over the range of from 0.0045 to $1.0073 \mathrm{mM}$. Parallel experiments were performed without the addition of adenine and the Lineweaver-Burk plots were compared.

The conditions for altering the medium $\mathrm{pH}$ have been previously published (14). Uptake in Krebs-Ringer phosphate buffer gassed with $100 \% \mathrm{O}_{2}$ over the $\mathrm{pH}$ range from 6.1 to 7.3 was compared with uptake in Krebs-Ringer bicarbonate in parallel experiments. In studies of sodium dependence on uptake, $\mathrm{NaCl}$ in the $\mathrm{KRB}$ was incrementally replaced with

${ }^{1}$ Abbreviations used in this paper: KRB, Krebs-Ringer bicarbonate buffer; $\mathrm{V}_{\max }$, maximum velocity.

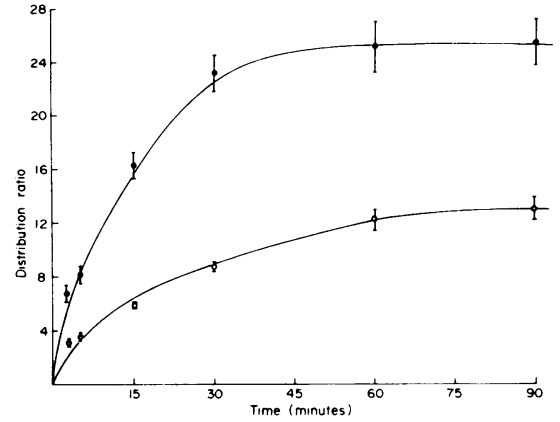

Figure 1 The uptake of hypoxanthine by isolated rat renal tubule fragments with time. Tubule fragments were incubated at $37^{\circ} \mathrm{C}$ in Krebs-Ringer bicarbonate buffer $(\mathrm{pH} 7.4$ ) with continuous gassing with $95 \% \mathrm{O}_{2} / 5 \% \mathrm{CO}_{2}$ in the presence of $0.02 \mathrm{mM}(\mathrm{O})$ or $0.1 \mathrm{mM}(\mathrm{O})\left[{ }^{14} \mathrm{C}\right]$ hypoxanthine. Distribution ratio is the ratio of counts per minute per milliliter of intracellular fluid to counts per minute per milliliter of medium. Each point represents the mean $\pm S E$ of at least six determinations.

choline chloride to give sodium concentrations of $25,50,75$, and $100 \mathrm{meq} / \mathrm{liter}$. In these studies, the tubules were preincubated in the various buffers for $10 \mathrm{~min}$ at $37^{\circ} \mathrm{C}$ with continuous gassing in $95 \% \mathrm{O}_{2} 5 \% \mathrm{CO}_{2}$ before initiation of uptake.

To determine the nature of the intracellular metabolites of hypoxanthine, cold trichloroacetic acid to give a final concentration of $5 \%(\mathrm{wt} / \mathrm{vol})$ was added to the tubule water extract obtained as described above after incubation. The resulting precipitate was then spun at $4^{\circ} \mathrm{C}$ and $33,000 \mathrm{~g}$, and the supernate was removed for chromatography. After resuspending and washing the precipitate twice with distilled water, it was solubilized in $0.5 \mathrm{ml}$ Soluene 100 (Packard Instrument Co., Downers Grove, Ill.) and added to $10 \mathrm{ml}$ of dilute Concentrol (Yorktown Research Inc., S. Hackensack, N. J.) for counting in a Packard Liquid Scintillation Spectrophotometer. The trichloroacetic acid supernate was neutralized with $\mathrm{KOH}$ and 10 $\mu l$ was chromatographed in two systems along with the unlabeled standards spotted over the supernate. In the first system, cellulose thin-layer plates precoated with $1 \%$ polyethyleneimine were developed with $1.25 \mathrm{M} \mathrm{NaCl}$ (15). The second system involved IVhatman 1 paper (IVhatman, Inc., Clifton, N. J.) developed in acetic acid: $n$-butanol: $\mathrm{H}_{2} \mathrm{O}(30: 120$ : 50) (16). Location of the spots was identified with an ultraviolet lamp $(254 \mu \mathrm{m})$. The chromatographs were cut in $1-\mathrm{cm}$ segments, which were assayed for radioactivity in Econofluor with liquid scintillation techniques.

All analyses of data for statistical significance were made with Student's $t$ test.

Materials. $\left[8-{ }^{14} \mathrm{C}\right] \mathrm{Hypoxanthine}$ was obtained from New England Nuclear, Boston, Mass. and was found to migrate with authentic hypoxanthine in the two chromatographic systems described above. Unlabeled hypoxanthine, inosine, and xanthine were obtained from Sigma Chemical Co., St. Louis, Mo. Uric acid was obtained from Pfanstiehl Laboratories, Inc., Waukegan, Ill. $p$-Aminohippuric acid and cellulose thinlayer plates were obtained from the Eastman Organic Chemicals Div., Eastman Kodak, Rochester, N. Y.

\section{RESULTS}

Time-dependent uptake. Fig. 1 shows the time-dependent uptake of 0.02 and $0.1 \mathrm{mM}\left[{ }^{14} \mathrm{C}\right]$ hypoxanthine. 
With $0.02 \mathrm{mM}$ hypoxanthine as the substrate, a distribution ratio of $6.70 \pm 0.67($ mean $\pm \mathrm{SE}$ ) occurred after $3 \mathrm{~min}$ of incubation and a steady-state level of $25.42 \pm 1.92$ was attained after $30 \mathrm{~min}$ with no statistically significant difference between the 30-, 60-, and 90-min time points. This is in distinct contrast to previous findings with cortical slices in which a steady state was not reached until after $4 \mathrm{~h}$ of incubation (9). With $0.1 \mathrm{mM}\left[{ }^{14} \mathrm{C}\right]-$ hypoxanthine as the substrate, the distribution ratio was $3.02 \pm 0.15$ after $3 \mathrm{~min}$ of incubation and remained lower than that seen with $0.02 \mathrm{mM}$ hypoxanthine at each time point, suggesting saturable uptake. Continuous gassing of the incubation media with $95 \% \mathrm{~N}_{2} 5 \%$ $\mathrm{CO}_{2}$ to demonstrate the effect of anoxia on the uptake of $0.02 \mathrm{mM}$ hypoxanthine lowered the distribution ratio to $2.10 \pm 0.13$ after $3 \mathrm{~min}$ of incubation, which was significantly different from the oxygenated control value $(P<0.001)$.

Metabolism of hypoxanthine. Radioactivity assay of the trichloroacetic acid-soluble fraction of the tubules revealed that more than $98 \%$ of the total ${ }^{14} \mathrm{C}$ taken up was present in this fraction. This was confirmed by finding only $1-2 \%$ of the total radioactivity to be associated with the trichloroacetic acid-insoluble fraction. Chromatography of the trichloroacetic acid-soluble fraction was performed after both 3 and 60 min of incubation with $0.02 \mathrm{mM}$ hypoxanthine. Fig. 2 shows the radioactivity along a thin-layer chromatogram with 1.25 M sodium chloride used to develop the polyethyleneimine-impregnated cellulose plate after a 3-min incubation. Almost half of the radioactivity is in the hypoxanthine area with most of the other counts being located in the nucleoside and nucleotide area. An average of five such determinations shows that $41 \%$ of the radioactivity is in the hypoxanthine area. There is little apparent conversion to xanthine, uric acid, or allantoin, which migrates with uric acid. The use of a descending paper chromatographic system developed with butanol, acetic acid, and water gives the same radioactivity relationships although the compounds are separated quite differently. Inosinic acid remains near the origin

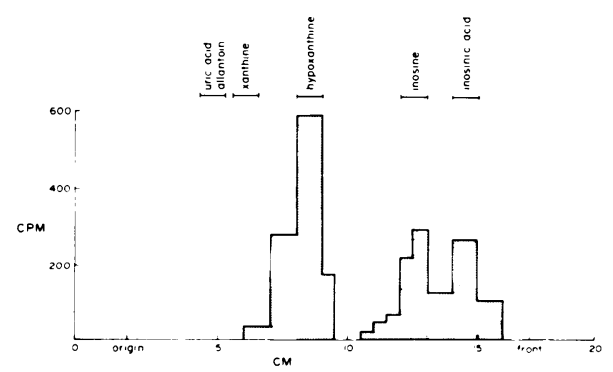

FIGURE 2 Thin-layer chromatography of an extract of isolated tubule fragments after incubation with radioactive hypoxanthine. Incubation time was $5 \mathrm{~min}$ and substrate concentration was $0.02 \mathrm{mM}$.

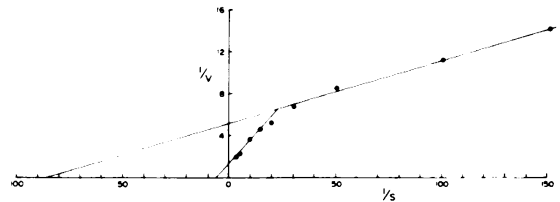

FIGURE 3 Lineweaver-Burk plot of the concentration dependence of uptake of hypoxanthine by isolated renal tubule fragments. Tubules were incubated for $3 \mathrm{~min}$. The initial concentration of hypoxanthine was varied over a range of $0.0066-0.287 \mathrm{mM}$. V represents the velocity of uptake (millimoles per liter intracellular fluid per $3 \mathrm{~min}$ ) and $S$ represents substrate concentration (millimolar). Each point represents the mean of at least four determinations.

$\left(R_{\mathrm{f}} 12\right)$; xanthine, inosine, and uric acid are separated considerably from inosinic acid $\left(R_{\mathrm{f}} 43,37\right.$ and 30 , respectively), and hypoxanthine is the fastest moving compound $\left(R_{\mathrm{f}} 49\right)$. Allantoin migrates very close to uric acid in this system. Chromatography revealed that after $60 \mathrm{~min}$ of incubation with $0.02 \mathrm{mM}$ hypoxanthine, $34 \%$ of the tissue radioactivity remained as hypoxanthine. Chromatography of the tissue radioactivity after $3 \mathrm{~min}$ of incubation with $0.1 \mathrm{~m} . \mathrm{M}$ hypoxanthine showed that $44 \%$ remained as hypoxanthine. Hypoxanthine was the only labeled compound detectable in the incubation medium over the entire 60 -min incubation period.

Because the pellet extract also includes the $\left[{ }^{14} \mathrm{C}\right]-$ hypoxanthine of the medium trapped in the pellet, a correction must be applied to determine the amount of $\left[{ }^{14} \mathrm{C}\right]$ hypoxanthine that represents intracellular material (17). When this is done, about $33 \%$ of the total intracellular radioactivity appears to be hypoxanthine after $3 \mathrm{~min}$ of incubation with both 0.02 and $0.1 \mathrm{mM}$ hypoxanthine and after $60 \mathrm{~min}$ with $0.02 \mathrm{mM}$ hypoxanthine. Thus, despite the extensive metabolism, the ${ }^{14} \mathrm{C}$ distribution ratios of 6.7 and 25.4 after 3 and $60 \mathrm{~min}$ of incubation with $0.02 \mathrm{mM}$ hypoxanthine represent a hypoxanthine distribution ratio of 2.3 and 8.5 , respectively, which is consistent with active transport.

Concentration dependence of the distribution ratio. To study the concentration dependence and saturability of hypoxanthine uptake, renal tubules were incubated with $\left[{ }^{14} \mathrm{C}\right]$ hypoxanthine plus unlabeled substrate to give final medium concentrations varying from 0.0066 to $0.287 \mathrm{mM}$. As can be seen from Fig. 3 a standard Lineweaver-Burk plot of these data gave a twolimbed curve, indicating that multiple transport systems were involved. From the Lineweaver-Burk plot an observed transport $K_{\mathrm{m} 1}$ of $0.012 \mathrm{mM}$ and a maximum velocity $\left(\mathrm{V}_{\max 1}\right)$ of $0.194 \mathrm{mmol} / \mathrm{liter}$ intracellular fluid per 3 min over the substrate concentration range of from 0.0066 to $0.033 \mathrm{mM}$ was determined. Over the range of higher substrate concentrations $(0.0495-0.287$ $\mathrm{mM}$ hypoxanthine) an observed transport $K_{\mathrm{m} 2}$ of 0.167 $\mathrm{mM}$ and $\mathrm{a} \mathrm{V}_{\max 2}$ of $0.782 \mathrm{mmol} / \mathrm{liter}$ intracellular fluid per 3 min was shown. 
Kinetic parameters can also be calculated from the observed transport data for a substrate with two carriermediated systems for uptake by the following equation:

$$
\mathrm{V} \text { observed }=\frac{\left(\mathrm{V}_{\max 1}\right)[\mathrm{S}]}{K_{\mathrm{m} 1}+[\mathrm{S}]}+\frac{\left(\mathrm{V}_{\max 2}\right)[\mathrm{S}]}{K_{\mathrm{m} 2}+[\mathrm{S}]},
$$

where $\mathrm{V}$ represents the velocity of uptake and $\mathrm{S}$ represents substrate concentration. Using the kinetic parameters determined from the Lineweaver-Burk plot as an initial estimate, kinetic parameters were calculated by nonlinear regression analysis with a Digital PDP12 computer (Digital Equipment Corp., Marlboro, Mass.) to give the best fit for the observed transport data employing Equation 1. The calculated transport kinetic parameters were $K_{\mathrm{m} 1}$ of $0.005 \mathrm{mM}$ and $\mathrm{V}_{\max 1}$ of 0.10 $\mathrm{mmol} / \mathrm{liter}$ intracellular fluid per $3 \mathrm{~min}$ for the low$K_{\mathrm{m}}$ system. The high- $K_{\mathrm{m}}$ system had kinetic parameters of $K_{\mathrm{m} 2}$ of $0.80 \mathrm{mM}$ and $\mathrm{V}_{\max 2}$ of $1.60 \mathrm{mmol} / \mathrm{liter}$ intracellular fluid per $3 \mathrm{~min}$.

These parameters have been calculated for total ${ }^{14} \mathrm{C}$ uptake and have not been corrected for the fraction in the form of metabolites. When this is done, a twolimbed Lineweaver-Burk plot for hypoxanthine is obtained with $K_{\mathrm{m}}$ values similar to those above. Only the $\mathrm{V}_{\max }$ values were diminished. Similar observations have been made for kinetics of proline transport in kidney cortex slices by Mohyuddin and Scriver (18) where proline is extensively oxidized to $\mathrm{CO}_{2}$. Our kinetic parameters have also been calculated without correction for a diffusion component, which is difficult to estimate in the face of avid uptake and metabolism and in view of the limited solubility of hypoxanthine, which proscribes incubations at very high substrate levels. Workers studying hypoxanthine uptake by other tissues have calculated kinetic parameters without determining a diffusion component (19-21). Indeed, Roth et al. (22) have shown that the kinetic parameters determined for glycine transport in rat renal tubules from uptake data that had been corrected for a diffusion component did not differ from the kinetic parameters determined from the same data when the diffusion component was not employed.

Influence of $p H$, temperature, and metabolic fuels. The effect of the medium hydrogen ion concentration on the distribution ratio after $5 \mathrm{~min}$ of incubation with $0.1 \mathrm{mM}$ hypoxanthine was studied by comparing the uptake in Krebs-Ringer phosphate buffer at 6.1, 6.5, 6.9, and 7.3 $\mathrm{pH}$ with the uptake in Krebs-Ringer bicarbonate buffer at $\mathrm{pH}$ 7.4. There was no significant difference in the distribution ratios over this range of $\mathrm{pH}$ 's. In an attempt to study the effect of medium $\mathrm{pH}$ 's over 7.4, bicarbonate of the Krebs-Ringer buffer was replaced with a 25-mM Tris (hydroxymethyl) aminomethane buffer (Tris). However, the effect of elevating the incubation $\mathrm{pH}$ above 7.4 could not be clearly
TABLE I

Effect of the Medium Sodium Concentration on Uptake of Hypoxanthine

\begin{tabular}{cc}
\hline Medium sodium & Distribution ratio \\
\hline meqliter & \\
143 & $10.18 \pm 0.41$ \\
100 & $8.66 \pm 0.05^{*}$ \\
75 & $7.52 \pm 0.39 \ddagger$ \\
50 & $6.33 \pm 0.28 \S$ \\
25 & $5.27 \pm 0.07 \S$ \\
\hline
\end{tabular}

Isolated renal tubule fragments were preincubated for 10 min in Krebs-Ringer bicarbonate buffer in which the $\mathrm{NaCl}$ was replaced with choline chloride meq/meq to give the stated medium sodium concentration. Incubation with 0.01 $\mathrm{mM}\left[{ }^{14} \mathrm{C}\right]$ hypoxanthine was then carried out. Each distribution ratio represents the mean $\pm \mathrm{SE}$ of at least four determinations.

* Significantly different from the distribution ratio in 143 meq/liter sodium buffer $P<0.02$.

\$ Significantly different from the distribution ratio in 143 meq/liter sodium buffer $P<0.01$.

$\$$ Significantly different from the distribution ratio in 143 meq/liter sodium buffer $P<0.001$.

discerned because the Tris buffer at $\mathrm{pH} 7.4$ caused a significant decrease in the distribution ratio after $5 \mathrm{~min}$ of incubation with $0.1 \mathrm{mM}$ hypoxanthine as the substrate when compared to uptake in KRB. A similar effect of Tris on the uptake of glycine in rat renal cortical slices has been shown (23). The addition of $10 \mathrm{mM}$ sodium acetate, sodium lactate, or glucose also had no significant effect on the distribution ratio of $0.1 \mathrm{mM}$ hypoxanthine after $3 \mathrm{~min}$ of incubation. When the incubation temperature was lowered to $20^{\circ} \mathrm{C}$, the distribution ratio of $0.01 \mathrm{mM}$ hypoxanthine after $3 \mathrm{~min}$ of incubation fell from the $37^{\circ} \mathrm{C}$ value of $10.40 \pm 0.70$ to $5.66 \pm 0.23(P<0.001, n=6)$.

Effect of medium sodium concentration. In Table I the effect of altering the medium sodium concentration can be seen. As the medium sodium concentration was reduced, there was a significant reduction in the distribution ratio of $0.01 \mathrm{mM}$ hypoxanthine after $5 \mathrm{~min}$ of incubation. The distribution ratio after $5 \mathrm{~min}$ of incubation with $0.1 \mathrm{mM}$ hypoxanthine in KRB containing $25 \mathrm{meq} / \mathrm{liter}$ of $\mathrm{Na}^{+}$was 2.56 \pm 0.19 , which is not significantly different from the control value of $2.95 \pm 0.16$ obtained after $5 \mathrm{~min}$ of incubation in KRB containing $143 \mathrm{meq} / \mathrm{liter}$ of $\mathrm{Na}^{+}$ ( $n=4$ determinations in each buffer). Because the effect of sodium on hypoxanthine uptake was observed with the low concentration of hypoxanthine where the majority $(77 \%)$ of uptake is mediated via the low$K_{\mathrm{m}}$ system, it seems likely that the sodium effect is on this system. 
The inhibitory effect of various compounds. The effect of a number of compounds on hypoxanthine uptake was studied and the results are presented in Table II. Two substrate concentrations of hypoxanthine were used, a low concentration $(0.01 \mathrm{mM})$ where transport is mediated predominantly $(77 \%)$ by the low$K_{\mathrm{m}}$ system and a higher concentration $(0.1 \mathrm{mM})$ where $65 \%$ of transport occurs via the high- $K_{\mathrm{m}}$ system. With the low substrate concentration, only the purine bases, adenine and guanine, and ribosylated hypoxanthine (inosine) at $1 \mathrm{mM}$ concentration inhibited hypoxanthine uptake. Guanine caused the greatest inhibition of the compounds examined. With the higher concentration of hypoxanthine all the compounds at $1 \mathrm{mM}$ and probenecid at $0.03 \mathrm{mM}$ caused a significant reduction in the uptake. Again, as with the low substrate concentration, guanine had the greatest effect on hypoxanthine uptake; however, the magnitude of the inhibition by guanine on the uptake of $0.1 \mathrm{mM}$ hypoxanthine could be accounted for by the inhibition of the low- $K_{\mathrm{m}}$ system alone.

To examine the nature of the inhibition by the purine bases, the effect of $0.83 \mathrm{mM}$ adenine on the uptake of hypoxanthine was studied. In Fig. 4, a Lineweaver-Burk plot for the substrate concentration range of from 0.0045 to $0.0414 \mathrm{mM}$ hypoxanthine with and without the addition of adenine is shown. Over this concentration range, the addition of $0.83 \mathrm{mM}$ adenine to the incubation media raised the $K_{\mathrm{m} 1}$ value from $0.012 \pm 0.001 \mathrm{mM}$ to $0.029 \pm 0.005 \mathrm{mM}(P<0.02)$ and lowered the $\mathrm{V}_{\max 1}$ from $0.320 \pm 0.016$ to $0.236 \pm 0.013$ $\mathrm{mmol} /$ liter intracellular fluid per $3 \mathrm{~min}(P<0.02)$, the means representing the data from three separate experiments. Over a higher concentration range of

TABLE II

Effect of Various Compounds on Hypoxanthine Uptake

\begin{tabular}{llll}
\hline & & \multicolumn{2}{c}{ Distribution ratio } \\
\cline { 3 - 4 } \multicolumn{1}{c}{ Compound added } & $\begin{array}{c}\text { Concen- } \\
\text { tration }\end{array}$ & $0.01 \mathrm{mM} \mathrm{Hyp}$ & $0.1 \mathrm{mM} \mathrm{Hyp}$ \\
\hline & $m . M$ & & \\
Control & & $11.55 \pm 0.41$ & $2.93 \pm 0.10$ \\
Uric acid & 1 & $12.57 \pm 0.42$ & $2.22 \pm 0.04^{*}$ \\
Xanthine & 1 & $10.93 \pm 0.31$ & $2.35 \pm 0.01^{*}$ \\
Probenecid & 0.03 & $11.26 \pm 0.58$ & $2.38 \pm 0.08$ \\
p-Aminohippurate & 1 & $11.63 \pm 0.55$ & \\
Adenine & 1 & $5.36 \pm 0.41^{*}$ & $2.23 \pm 0.04^{*}$ \\
Guanine & 1 & $1.74 \pm 0.06^{*}$ & $1.79 \pm 0.04^{*}$ \\
Inosine & 1 & $4.68 \pm 0.06^{*}$ & \\
& & &
\end{tabular}

Isolated rat renal tubules were incubated for $3 \mathrm{~min}$ with either 0.1 or $0.01 \mathrm{mM}\left[{ }^{14} \mathrm{C}\right]$ hypoxanthine $(\mathrm{Hyp})$ in the presence of various compounds. Each distribution ratio represents the mean $\pm \mathrm{SE}$ for at least four determinations.

* Significantly different from control, $P<0.001$.

$\ddagger$ Significantly different from control, $P<0.01$.

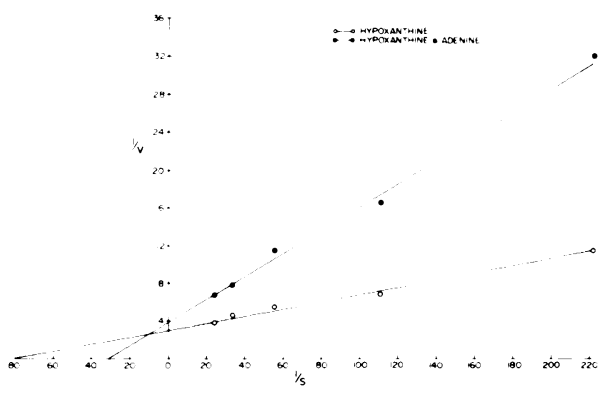

Figure 4 Effect of adenine on the Lineweaver-Burk plot of concentration dependence of uptake of hypoxanthine in isolated renal tubule fragments. Tubule fragments were incubated with $(O)$ or without (O) $0.83 \mathrm{mM}$ adenine. V represents velocity of uptake (millimoles per liter intracellular fluid per $3 \mathrm{~min}$ ), and $S$ represents substrate concentration (millimolar). Each point represents the mean of six determinations.

hypoxanthine $(0.1009-1.0073 \mathrm{mM})$, the nature of the inhibition could not be clearly discerned because the low- $K_{\mathrm{m}}$ system contributes a significant fraction to the total uptake and the inhibition of adenine on this fraction of uptake via the low- $K_{\mathrm{m}}$ system could not be dissociated from a possible inhibition of the fraction of uptake via the high- $K_{m}$ system. Because of the limited solubility at $\mathrm{pH} 7.4$, high concentrations of hypoxanthine to clarify this further are not possible.

\section{DISCUSSION}

Studies of concentrative hypoxanthine uptake by rabbit renal cortex slices have been reported by Berndt (9). The uptake by slices was however, slow, requiring 3-4 $\mathrm{h}$ to attain a steady state. Effects of metabolic inhibitors and the interaction of other purines were demonstrated only with 3- or 4-h incubations. The data indicated that purine bases, adenine and guanine, inhibited hypoxanthine uptake, but that uric acid had caused only a slight inhibitory effect and xanthine none at all.

In our experiments the uptake of hypoxanthine with isolated rat cortical tubule fragments was rapid reaching a steady state in one-sixth of the time required by cortical slices. With isolated tubules it was possible to determine the initial rate of uptake after $3 \mathrm{~min}$ of incubation allowing analysis of the kinetic parameters of hypoxanthine uptake. Two saturable systems appeared to mediate this uptake. From a LineweaverBurk plot, the observed low $-K_{m}$ system had a value of $0.012 \mathrm{mM}$ and the observed high- $K_{\mathrm{m}}$ system had a value of $0.167 \mathrm{mM}$. The calculated values for the lowand high- $K_{\mathrm{m}}$ systems were 0.005 and $0.80 \mathrm{mM}$, respectively, using Eq. 1. By either method there is at least a 14-fold difference between the two $K_{\mathrm{m}}$ values, strongly suggesting that there are, in fact, two 
systems mediating hypoxanthine transport into the renal tubule cell.

We found significant metabolism of labeled hypoxanthine to inosine and inosinic acid, but not to uric acid, xanthine, or allantoin. The chromatographic systems that we employed did not clearly separate inosinic acid from other purine nucleotides, and it is possible that some adenosine monophosphate was formed. In contrast, Berndt found no metabolism of hypoxanthine in most experiments with rabbit cortical slices although small amounts of inosinic acid were detected in a few experiments (9). The difference in the metabolism of hypoxanthine between our study and that of Berndt may be in our use of rat kidney. In our hands, however, the chromatographic system Berndt employed for metabolite detection did not adequately separate hypoxanthine from its metabolites.

Although metabolism of hypoxanthine occurred and hypoxanthine derivatives were formed, a third of the intracellular pool of radioactivity remained as unchanged hypoxanthine after 3 and $60 \mathrm{~min}$ of incubation. The ratio of the intracellular to medium concentration of unmetabolized hypoxanthine was greater than unity reaching eight at the steady state, thus demonstrating concentrative uptake of hypoxanthine itself.

The values we determined for the transport $K_{\mathrm{m}}$ 's are in the same range as those determined in other tissues. In the erythrocyte Lassen (24) found only one saturable transport system for hypoxanthine with a transport $K_{\mathrm{m}}$ of $0.400 \mathrm{mM}$. Benke et al. (21) also found one saturable transport system in cultured human skin fibroblasts with a transport $K_{\mathrm{m}}$ of $0.003-$ $0.007 \mathrm{mM}$ as did Zylka and Plagemann (19) in cultured Novikoff hepatoma cells. In cultured Chinese hamster lung fibroblasts, Alford and Barnes (20) demonstrated two saturable transport systems with transport $K_{\mathrm{m}}$ 's of 0.020 and $0.600 \mathrm{mM}$. In all of these studies, the velocity of uptake was derived from the total of hypoxanthine and its metabolites in the tissue. Berndt (9), who worked with renal cortical slices, did not determine the dependence of hypoxanthine uptake on its concentration.

From the data on inhibition of hypoxanthine uptake by certain selected compounds, some speculations may be made about the specificity of the two systems we described for hypoxanthine transport in renal tubule cells. With a low concentration of hypoxanthine $(0.01 \mathrm{mM})$ as the substrate, $77 \%$ of the total uptake is mediated by the low- $K_{m}$ system. Xanthine, uric acid, $p$-aminohippurate, and probenecid had no effect on the uptake of hypoxanthine when it was mediated primarily by the low- $K_{\mathrm{m}}$ system. In contrast, adenine and guanine do inhibit hypoxanthine uptake by this system. Guanine was the most potent inhibitor of $0.01 \mathrm{mM}$ hypoxanthine uptake, the $83 \%$ reduction by $1 \mathrm{mM}$ guanine being equal to that observed if $1 \mathrm{mM}$ hypoxanthine were used instead.

It appears from these data that the low $-K_{\mathrm{m}}$ system for hypoxanthine may be involved in purine base transport. The substitution of an amino group at position 6 of the purine rings lessened the magnitude of the inhibition as seen by the effect of adenine when compared to guanine on the uptake of $0.01 \mathrm{mM}$ hypoxanthine. The addition of an hydroxyl group on positions 2 and 8 forming xanthine and uric acid, respectively, completely obliterated the inhibition. Finally, the organic acids, $p$-aminohippurate and probenecid, which inhibit the oxypurines, xanthine and uric acid, had no effect on hypoxanthine transport by the low- $K_{\mathrm{m}}$ system.

At $0.1 \mathrm{mM}$ hypoxanthine concentration, where $65 \%$ of the uptake was mediated by the high- $K_{\mathrm{m}}$ system as determined by Eq. 1, all the compounds tested were inhibitory. Because there was no effect on the low- $K_{\mathrm{m}}$ system by xanthine, uric acid, or probenecid, the inhibition seen with $0.1 \mathrm{mM}$ hypoxanthine must be caused by an effect on the high- $K_{\mathrm{m}}$ system. As was seen with the low concentration of hypoxanthine, adenine, and, to an even greater extent, guanine inhibited hypoxanthine uptake with the higher substrate concentration. However, this inhibition by the purine bases probably represents an effect on that portion of transport mediated by the low- $K_{\mathrm{m}}$ system although an effect on the high- $K_{m}$ system cannot be completely excluded.

With this analysis of the kinetics of hypoxanthine transport into renal tubule cells, comparisons of our data to that of previous investigators on the nature of oxypurine handling by the kidney may be made. Goldfinger et al. (7), by clearance techniques under conditions of increased plasma oxypurine levels, found that despite the structural similarities of the oxypurines, hypoxanthine and xanthine, to uric acid there appears to be separate systems mediating their transport in the renal tubule because probenecid increased uric acid excretion and decreased the combined excretion of hypoxanthine and xanthine. This study did not determine whether this decrease was caused by a decrease in hypoxanthine excretion or in xanthine excretion, or both. Gjorup and Poulsen (25) found no effect of probenecid on the clearance of oxypurines in gouty patients with normal oxypurine levels. In support of these data, we found no effect of probenecid on the low- $K_{\mathrm{m}}$ system that would mediate over $80 \%$ of the transport at normal plasma levels. Probenecid did affect uptake via the high- $K_{\mathrm{m}}$ system that would account for a significant fraction of the uptake at the raised plasma levels studied by Goldfinger et al. (7). Recently, Auscher et al. (8) presented data for separate renal handling of hypoxanthine from xanthine because xanthine, but not hypoxanthine, was suppressible with 
the administration of pyrazinoic acid to a xanthinuric patient. Our data also suggest differences in the uptake of xanthine and hypoxanthine into the renal tubule cells, because xanthine inhibited only the high$K_{\mathrm{m}}$ system for hypoxanthine uptake. From our studies, hypoxanthine uptake at physiologic concentrations appears to be mediated primarily by the low- $K_{\mathrm{m}}$ system, which is shared with the other purine bases. The high- $K_{\mathrm{m}}$ system, which is shared by other oxypurines and organic acids, is less important for hypoxanthine uptake at physiologic concentrations, but assumes greater importance with raised hypoxanthine concentrations.

\section{ACKNOWLEDGMENTS}

This work was supported by grants AM 10894 and HD 07107 from the National Institutes of Health, Bethesda, Md.

\section{REFERENCES}

1. Elron, G. B., S. Callahan, H. Nathan, S. Bieber, R. W. Rundles, and G. H. Hitchings. 1963. Potentiation by inhibition of drug degradation: 6-substituted purines and xanthine oxidase. Biochem. Pharmacol. 12: 85-93.

2. Rundles, R. W., J. B. Wyngaarden, G. H. Hitchings, G. B. Elron, and H. R. Silberman. 1963. Effects of a xanthine oxidase inhibitor on thiopurine metabolism, hyperuricemia and gout. Trans. Ass. Amer. Physicians. 76: $126-140$.

3. Klinenberg, J. R., S. E. Goldfinger, and J. E. Seegmiller. 1965. The effectiveness of the xanthine oxidase inhibitor allopurinol in the treatment of gout. Ann. Intern. Med. 62: 639-647.

4. Green, M. L., W. Y. Fujimoto, and J. E. Seegmiller. 1969. Urinary xanthine stones - rare complication of allopurinol therapy. N. Engl. J. Med. 280: 426-427.

5. Dickinson, C. F., and J. M. Smellie. 1959. Xanthinuria. Br. Med.J. 2: 1217-1221.

6. Engelman, K., R. W. E. Watts, J. R. Klinenberg, A. Sjoerdsma, and J. E. Seegmiller. 1964. Clinical, physiological, and biochemical studies of a patient with xanthinuria and pheochromocytoma. Am. J. Med. 37: 839-861.

7. Goldfinger, S., J. R. Klinenberg, and J. E. Seegmiller. 1965. The renal excretion of oxypurines. J. Clin. Invest. 44: 623-628.

8. Auscher, C., C. Pasquier, P. Peheut, and F. Delbarre. 1978. Study of urinary pyrazinamide metabolites and their action on the renal excretion of xanthine and hypoxanthine in a xanthinuric patient. Biomed. Express. (Paris). 28: 129-133.

9. Berndt, W. O. The accumulation of ${ }^{14} \mathrm{C}$-hypoxanthine by slices of rabbit kidney cortex. 1968. Biochem. Pharmacol. 17: 605-615.

10. Burg, M. B. and J. Orloff. 1962. Oxygen consumption and active transport in separated renal tubules. Am. J. Physiol. 203: 327-330.

11. Roth, K. S., S. M. Hwang, and S. Segal. 1976. Effects of maleic acid on the kinetics of $\alpha$-methyl-D-glucoside uptake by isolated rat renal tubules. Biochim. Biophys. Acta. 426: 675-687.

12. McNamara, P. D., C. Rea, and S. Segal. 1971. Sugar transport: effect of temperature on concentrative uptake of $\alpha$-methylglucoside by kidney cortex slices. Science (Wash. D. C.). 172: 1033-1034.

13. Rosenberg, L. E., A. Blair, and S. Segal. 1961. Transport of amino acids by slices of rat kidney cortex. Biochim. Biophys. Acta. 54: 479-488.

14. Segal, S., L. Schwartzman, A. Blair, and D. Bertoli. 1967. Dibasic amino acid transport in rat kidney cortex slices. Biochim. Biophys. Acta. 135: 127-135.

15. Jones, C. E., E. E. Smith, W. Hicks, and J. W. Crowell. 1970. Determination of urinary purines in hyperuricosuric children by thin-layer chromatography.J. Lab. Clin. Med. 76: $163-170$.

16. Thomson, R. Y. 1960. Purines and pyrimidines and their derivatives. In Chromatographic and Electrophoretic Techniques. Vol. I. I. Smith, editor. W. S. Heinemann Imported Books and Interscience Publishers, Inc., New York. 231-245.

17. Segal, S., and J. C. Crawhall. 1967. Transport of cysteine by human kidney cortex in vitro. Biochem. Med. 1: $141-150$.

18. Mohyuddin, F., and C. R. Scriver. 1970. Amino acid transport in mammalian kidney: multiple systems for amino acids and glycine in rat kidney. Am. J. Physiol. 219: $1-8$.

19. Zylka, J., and P. G. W. Plagemann. 1975. Purine and pyrimidine transport by cultured Novikoff cells: Specificities and mechanisms of transport and relationship to phosphoribosylation. J. Biol. Chem. 250: 5756-5767.

20. Alford, B. L., and E. M. Barnes. 1976. Hypoxanthine transport by cultured Chinese hamster lung fibroblasts. J. Biol. Chem. 251: 4823-4827.

21. Benke, P. J., N. Herrick, and A. Hebert. 1973. Transport of hypoxanthine in fibroblasts with normal and mutant hypoxanthine-guanine phosphoribosyltransferase. Biochem. Med. 8: 309-323.

22. Roth, K. S., S. M. Hwang, J. W. London, and S. Segal. 1977. Ontogeny of glycine transport in isolated rat renal tubules. Am. J. Physiol. 233: F241-F246.

23. Reynolds, R., K. S. Roth, S. M. Hwang, and S. Segal. On the development of the glycine transport systems by rat renal cortex. Biochim. Biophys. Acta. In press.

24. Lassen, U. V. 1967. Hypoxanthine transport in human erythrocytes. Biochim. Biophys. Acta. 135: 146-154.

25. Gjorup, S., and H. Poulsen. 1955. Effects of probenecid, cinchophen, and colchicine on the plasma concentration and renal excretion of oxypurines in patients with gout. Acta Pharmacol. Toxicol. 11: 343-352. 